\title{
Global changes in mortality rates in polytrauma patients admitted to the ICU—a systematic review
}

\author{
Johanna M. M. van Breugel ${ }^{1 *}$ (D, Menco J. S. Niemeyer ${ }^{1}$, Roderick M. Houwert ${ }^{1}$, Rolf H. H. Groenwold²,
} Luke P. H. Leenen ${ }^{1}$ and Karlijn J. P. van Wessem ${ }^{1}$

\begin{abstract}
Background: Many factors of trauma care have changed in the last decades. This review investigated the effect of these changes on global all-cause and cause-specific mortality in polytrauma patients admitted to the intensive care unit (ICU). Moreover, changes in trauma mechanism over time and differences between continents were analyzed.

Main body: A systematic review of literature on all-cause mortality in polytrauma patients admitted to ICU was conducted. All-cause and cause-specific mortality rates were extracted as well as trauma mechanism of each patient. Poisson regression analysis was used to model time trends in all-cause and cause-specific mortality. Thirty studies, which reported mortality rates for 82,272 patients, were included and showed a decrease of 1.8\% (95\% Cl 1.6-2.0\%) in all-cause mortality per year since 1966. The relative contribution of brain injury-related death has increased over the years, whereas the relative contribution of death due to multiple organ dysfunction syndrome (MODS), acute respiratory distress syndrome, and sepsis decreased. MODS was the most common cause of death in North America, and brain-related death was the most common in Asia, South America, and Europe. Penetrating trauma was most often reported in North America and Asia.

Conclusions: All-cause mortality in polytrauma patients admitted to the ICU has decreased over the last decades. A shift from MODS to brain-related death was observed. Geographical differences in cause-specific mortality were present, which may provide region-specific learning possibilities resulting in improvement of global trauma care.
\end{abstract}

Keywords: Trauma care, Polytrauma patients, Intensive care unit, Mortality

\section{Background}

Trauma is the leading cause of death and disability worldwide. Over five million people worldwide are killed annually due to injury resulting from traffic accidents, falls, drowning, burns, poisoning, (self-inflicted) violence, or acts of war. These deaths account for 9\% of global mortality-more than that of HIV/AIDS, malaria, and

\footnotetext{
*Correspondence: j.m.m.vanbreugel-4@umcutrecht.nl

'Department of Trauma Surgery, University Medical Center Utrecht, Heidelberglaan 100, 3585 GA Utrecht, The Netherlands

Full list of author information is available at the end of the article
}

tuberculosis combined. For each death, there are many more hospitalizations, emergency department visits, and doctor's appointments $[1,2]$. Despite many improvements in primary, secondary, and tertiary prevention, e.g., legislation, introduction of computed tomography $(\mathrm{CT})$, and development of advanced trauma life support (ATLS), these numbers show that still there are many trauma victims, and more preventative, diagnostic, and therapeutic options are necessary to reduce these numbers [3].

Several studies have shown that many trauma patients die at a very early stage, either on-site or within the first

(c) The Author(s). 2020 Open Access This article is licensed under a Creative Commons Attribution 4.0 International License, which permits use, sharing, adaptation, distribution and reproduction in any medium or format, as long as you give appropriate credit to the original author(s) and the source, provide a link to the Creative Commons licence, and indicate if changes were made. The images or other third party material in this article are included in the article's Creative Commons licence, unless indicated otherwise in a credit line to the material. If material is not included in the article's Creative Commons licence and your intended use is not permitted by statutory regulation or exceeds the permitted use, you will need to obtain permission directly from the copyright holder. To view a copy of this licence, visit http://creativecommons.org/licenses/by/4.0/ The Creative Commons Public Domain Dedication waiver (http://creativecommons.org/publicdomain/zero/1.0/) applies to the data made available in this article, unless otherwise stated in a credit line to the data. 
$48 \mathrm{~h}$ after admission [4-6]. However, improvements in injury prevention and trauma care may have caused a right-shift in time of mortality after injury suggesting there has been a shift from a trimodal to a bimodal distribution [3, 6]. Longer survival implicates more intensive care unit (ICU) admissions, rendering improvements in ICU care essential. However, an overview article providing insight in mortality rates of global trauma care is lacking. Such an article could offer important insights in aspects that require further improvement of care as well as research.

The main objective of this systematic review was to assess whether there has been a change in all-cause mortality in polytrauma patients admitted to the ICU. This research's aim was subdivided in assessing (1) changes in the specific causes of death and (2) differences between geographical locations. A second objective was to assess whether there have been changes in trauma mechanism worldwide.

\section{Methods}

\section{Search and selection}

A systematic review of all published literature according to the Preferred Reporting Items for Systematic Reviews and Meta-Analyses (PRISMA) guidelines was conducted [7]. We aimed to identify all studies that reported on mortality in polytrauma patients (injury severity score $($ ISS $)>15$ ) admitted to the ICU. On the 26th of February 2020, we systematically searched the PubMed, Cochrane library, and Embase databases. The search terms "polytrauma", "ICU", and "mortality" plus their plural forms and synonyms were used. The complete search strings are provided in Appendix 1. Duplicates were removed using an online screening program (Rayyan [8]), and all remaining articles were independently screened by JvB and MN based on the title and abstract. Potentially relevant papers were selected, and full texts were obtained. When correspondence details of the authors were available, they were contacted in case the full text could not be obtained online or from our university library. Articles were excluded when no full text was available; when title, abstract, or full text was not in English, German, French, Spanish, or Dutch; when only a specific subset of trauma patients was researched, e.g., solely severe thoracic trauma; when all included patients suffered from a specific condition e.g., sepsis; and when it concerned reviews or conference abstracts. The references of included papers were screened using the same criteria, as well as the references of relevant and related reviews.

\section{Quality assessment}

Elements from the Critical Appraisal Skills Programme (CAPS), the Methodological Index for Non-Randomized
Studies instrument (MINORS), and the Risk of Bias in Non-Randomized Studies of Interventions (ROBINS-I) tool were used to assess the methodological quality of eligible articles [9-11]. Elements included in this assessment comprised clarity and relevance of the study aim, study design, and different types of bias, e.g., selection, detection, and reporting bias. An example of selection bias is when patients were not consecutively included. An example of reporting bias is when the authors did not describe clearly how the cause of death was determined. Suppressing or revealing information selectively is an example of reporting bias. Similar to the MINORS instrument, a score of 0,1 , or 2 points was awarded for each criterion: 0 points were assigned when an item was not reported, 1 point when an item was reported but inadequately, and 2 points when an item was adequately reported, leading to a maximum of 12 points per study.

\section{Outcome}

Data on all-cause mortality, cause-specific mortality, mechanism of injury, and geographical location were extracted from the included articles. The end of data collection from each included study was used (instead of the year of publication) for all analyses to place the data in the right time frame. Cause-specific mortality was stratified in brain injury, thoracic injury, abdominal injury, death by exsanguination, multiple organ dysfunction syndrome (MODS, definitions used by the included articles are shown in Table 1), acute respiratory distress syndrome (ARDS, Table 1), sepsis (Table 1), and death from a cardiac cause. Other causes were categorized as "miscellaneous". Mechanism of injury was stratified in blunt and penetrating trauma. A second, more detailed analysis for trauma mechanism was performed by using the following categories: traffic accidents, falls from height, workplace accidents, suicide, assault, penetrating injury, and miscellaneous.

\section{Statistical analysis}

Trends in all-cause mortality and cause-specific mortality over time were visualized and analyzed using Poisson regression models (R Core Team (2015). R: a language and environment for statistical computing. R Foundation for Statistical Computing, Vienna, Austria. URL https:// www.R-project.org/). A $p$ value $<0.05$ was considered statistically significant.

\section{Results}

Search

The initial search identified 2704 articles (Fig. 1). One additional article was obtained through personal knowledge of one of the authors. We excluded 429 duplicates after which 2276 articles remained. These were screened by JvB and $\mathrm{MN}$ based on their title and abstract. Full 


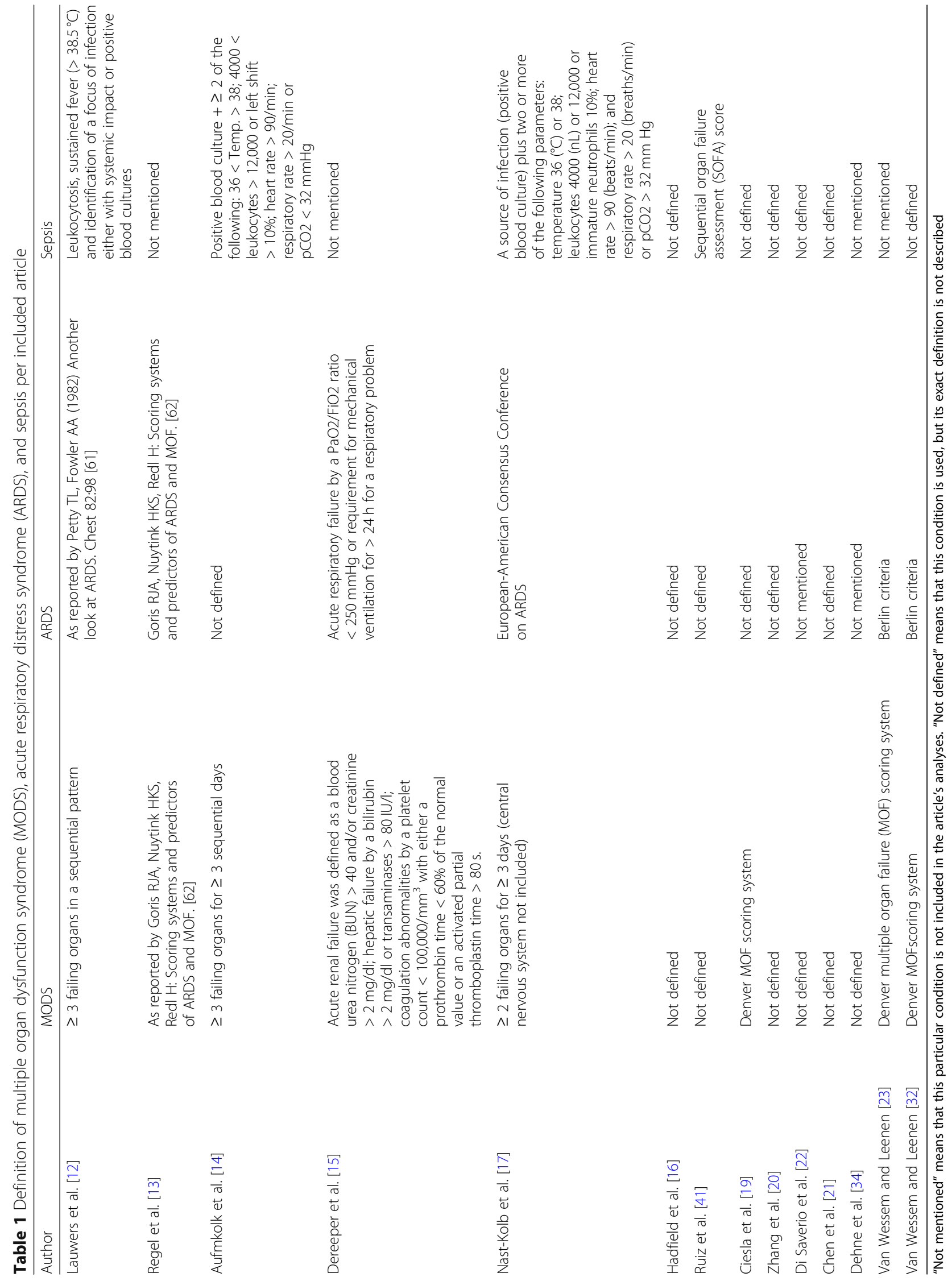




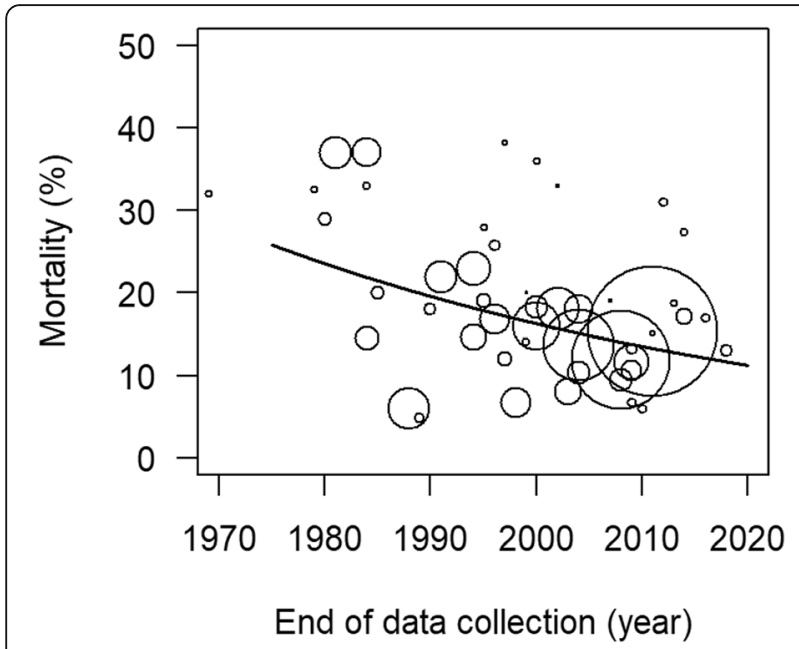

Fig. 1 PRISMA flowchart of search, screening, and inclusion strategy

texts were then obtained whenever possible. In total, 30 articles were found eligible for this review [12-32]. All references and citations from these 30 articles were screened and identified in Web of Science. However, this did not result in additional relevant articles.

\section{Characteristics of the studies and study populations}

An overview of the study characteristics is provided in Table 2. Thirty studies published between 1985 and 2018 were included in this review with a total of 82,272 patients. Inclusion criteria varied per study and ranged from multiple criteria, such as a minimum ISS or age, to no additional criteria apart from "polytrauma patients" and "admission to the ICU." Also, the number of included patients varied widely from 20 to 31,154 patients, as well as the study duration with a minimum of 1.5-2 years in the study of Dereeper et al. [15] and a maximum of 30 years for the study of Probst et al. [28]. Most studies were carried out in Europe, and especially Germany was well represented $([12-14,17,28,29,31,33-37] 12$ out of 19 European studies [12-17, 22, 23, 25, 26, 28, 29, 31-36, 38] were German). Four studies took place in Asia [18, 20, 21, 37], three in the USA [19, 27, 39], two in South America [40, 41], and two in Australia [24, 30].

\section{Quality of the included articles}

An overview of the quality of the included studies is given in Table 3. All studies apart from one [21] clearly described their study design. Most studies were retrospective, although data was sometimes collected prospectively in a trauma registry. There was no indication for selection bias in all 30 studies except for three [33, 34, 37]. Either patients were not consecutively included or the inclusion process was not clearly described in these articles. Five studies did not clearly describe how they obtained data on the cause of death $[12,13,20,21$,
25]. Eleven studies scored the maximum number of points [19, 22, 23, 27, 29-32, 41-43]. The lowest score was five points [37].

\section{All-cause mortality}

All 30 papers reported all-cause mortality rates in their study population (Table 1). Seven studies stratified their total study duration in smaller time spans and reported mortality rates for each time span $[13,17,22,25,28,29$, 31]. All available information was included in our analysis of all-cause mortality.

All-cause mortality rates in polytrauma patients admitted to the ICU was observed to decrease over time (Fig. 2). We note that there was substantial variation between studies. For example, the study by Mazandarani et al. [37] showed a relatively high mortality (31\%) considering its time period (2012), whereas Goins et al. reported a relatively low mortality (6\%) for its time period (1988) [27]. Mortality decreased with approximately $1.8 \%$ per year (95\% confidence interval $(\mathrm{CI}) 1.6-2.0 \%, p<0.001)$.

\section{Changes in cause of death over time}

Fifteen of the included articles reported data on the individual causes of death $[12-17,19-23,32,34,36,41]$. One paper provided date from five independent time periods leading to a total of 19 data points [17]. Multiple organ dysfunction syndrome (MODS) was reported as the main cause of death in several studies until the end of the last century $[13,14,17]$. At the turn of the century, this altered and brain injury often became the leading cause of death. Figure 3 shows the relative contributions (cause-specific mortality as a percentage of all ICU mortality in trauma patients admitted to the ICU). The relative contribution to ICU mortality of MODS, ARDS, and sepsis decreased over time: relative decreases per year of 1.9\% (95\% CI 1.2-2.7\%), 8.4\% (95\% CI $6.0-10.6 \%$ ), and $1.7 \%$ (95\% CI $0.5-2.9 \%)$, respectively. In conjunction with this decrease, an increase was observed for the relative contribution to ICU mortality of brain injury and hemorrhage: relative increases per year of $2.5 \%$ (95\% CI $1.9-3.0 \%$ ) and $1.9 \%$ (95\% CI $1.0-2.9 \%$ ), respectively.

\section{Changes in trauma mechanism over time}

Thirteen of the 30 included articles provided data on mechanism of injury sustained by their study population [12, 14-16, 20-22, 26, 27, 36, 37, 39, 40]. There have been no changes in the ratio of blunt and penetrating trauma over time (Fig. 4a). Traffic accidents were the most prevalent trauma mechanism reported in all articles, although there has been a decrease of approximately $25 \%$ in almost 25 years (Fig. 4b). Falls and workplace accidents were often reported as the second most common trauma mechanism. Assault, suicide 


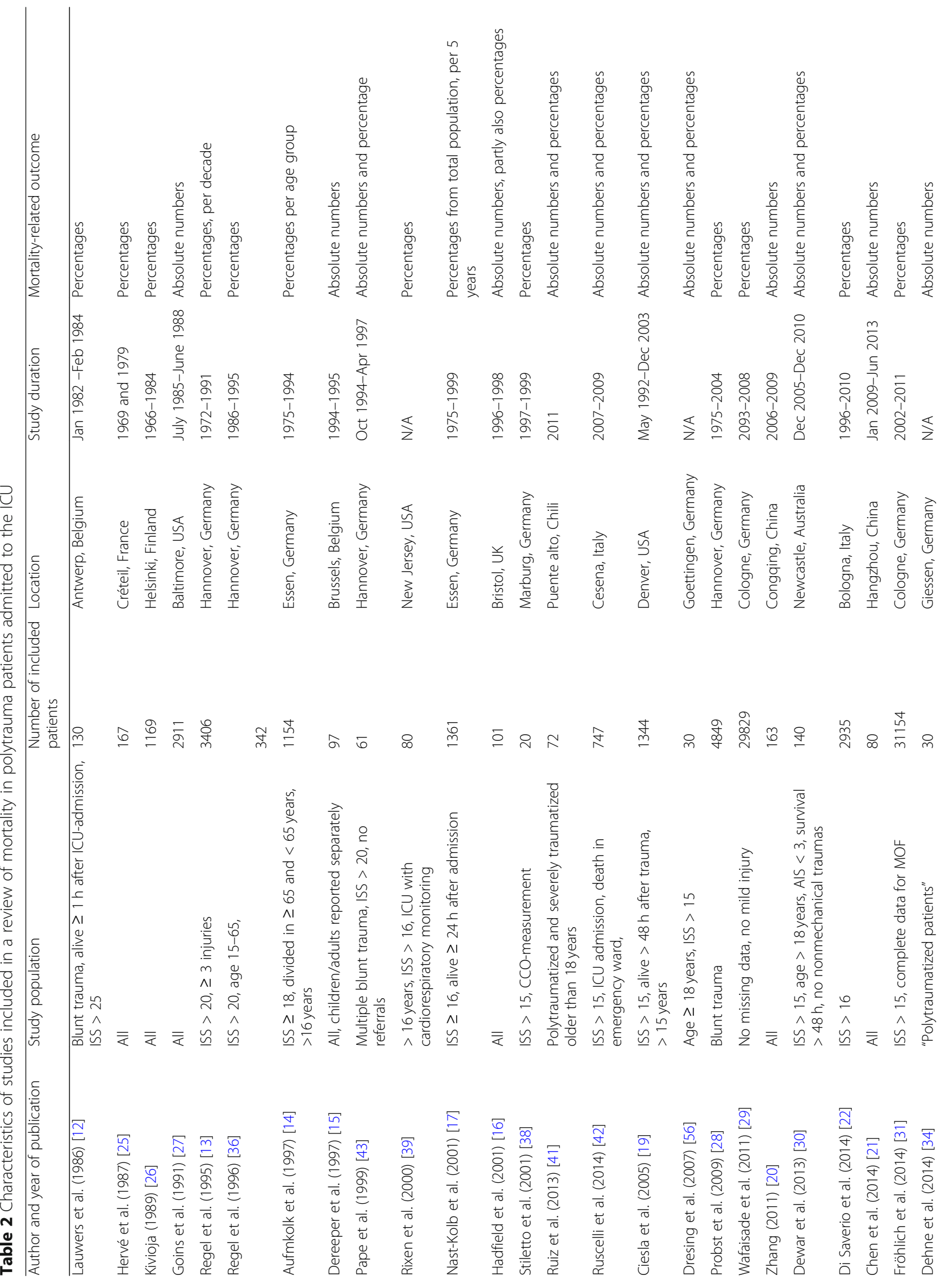




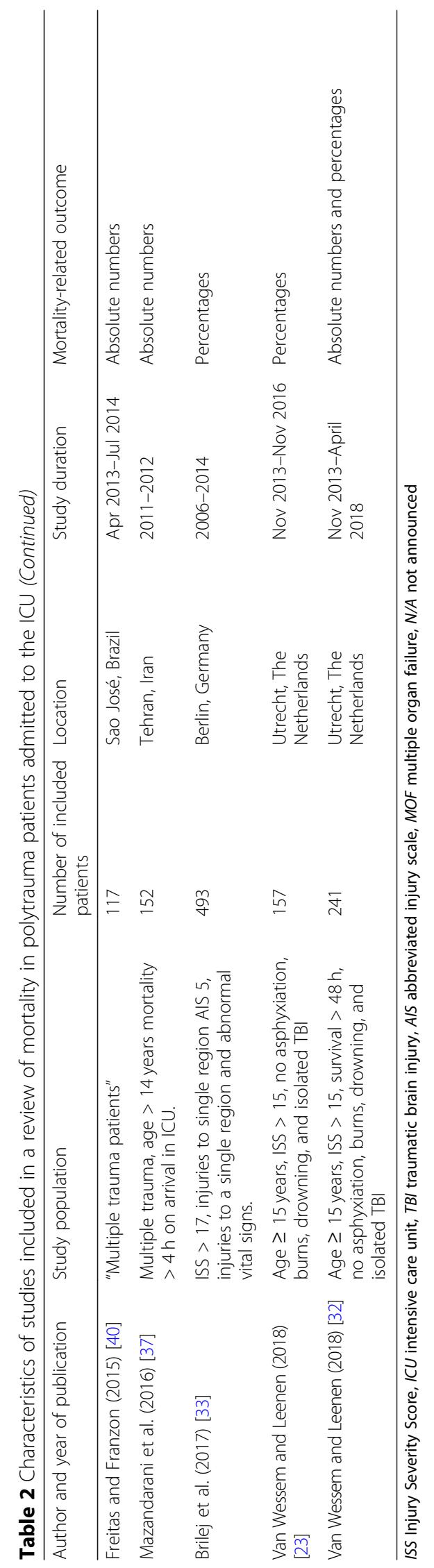




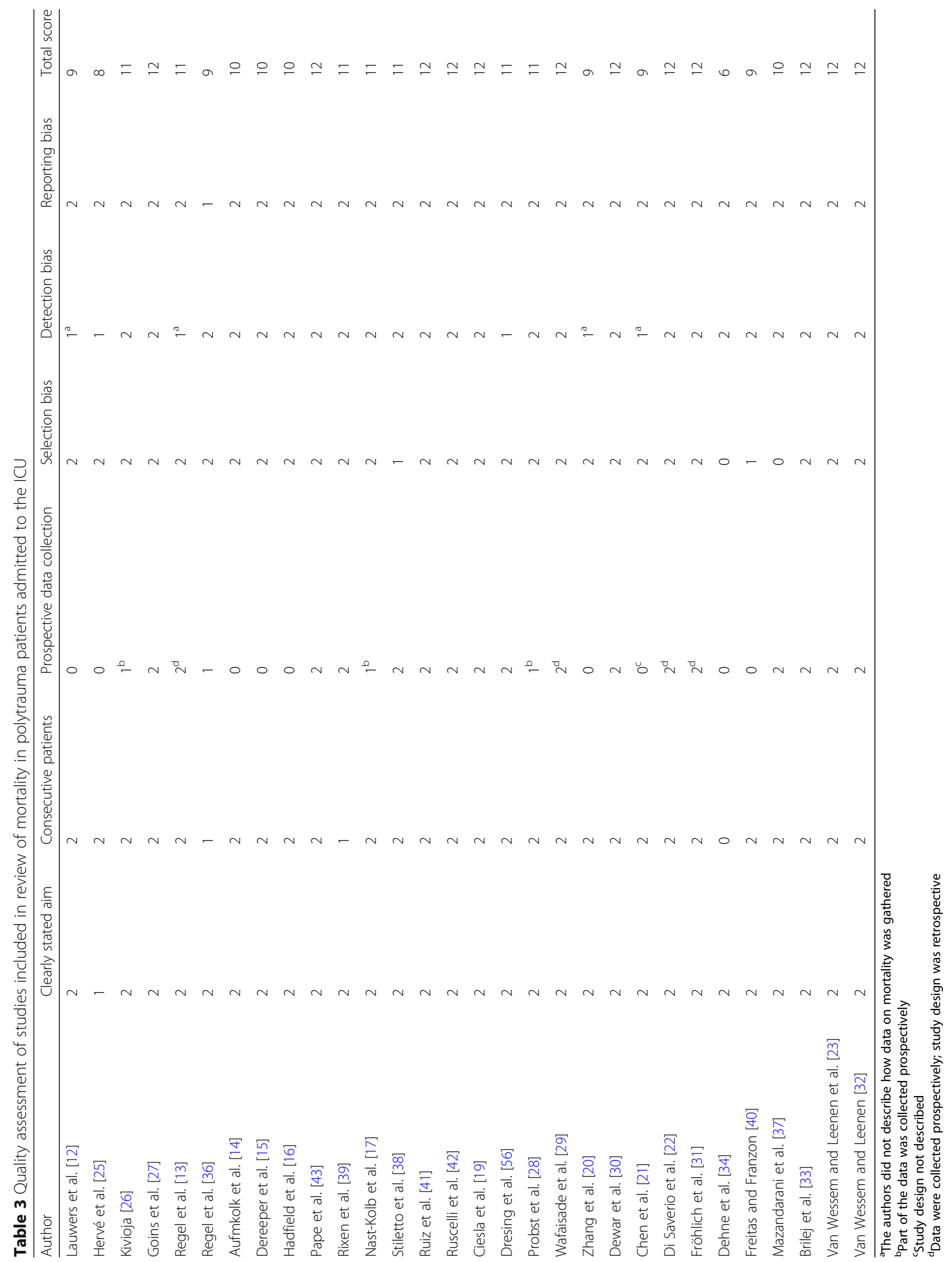


attempts, accidental injuries, and penetrating injuries (stab wounds as well as gunshot wounds) were all less common causes of trauma, but were similarly prevalent throughout all years.

\section{Geographical differences in trauma mechanism and causes of death}

The included articles were divided into subgroups representing the continent of the study population. First, differences in all-cause mortality between continents were analyzed for studies published after 2000 to reduce temporal influences (Table 1, Europe $n=17$, South America $n=2$, North America $n=2$, Asia $n=3$ ) (Fig. 4). Weighted averages based on the study population of each study resulted in $14.4 \%$ all-cause mortality for Europe, $22.6 \%$ for South America, 9.6\% for North America, and $18.5 \%$ for Asia. Further analyses on geographical differences, such as blunt/penetrating trauma and the most prevalent cause of death, can be found in Appendix 2.

\section{Discussion}

This systematic review of all-cause mortality in polytrauma patients admitted to the ICU showed that over the last 35 years all-cause mortality decreased by approximately $1.8 \%$ per year. Analysis of cause-specific mortality suggests that this is mainly attributable to decreases in MODS-related and ARDS-related mortality. Mortality due to brain injury on the other hand increased. These observed relative increases and decreases should be seen in relation to each other as all-cause mortality decreased substantially. More specifically, before the turn of the century, organ failure was a more prevalent cause of death than brain injury. These findings are in line with the results from the study by Trunkey [5]. He suggested a trimodal distribution of immediate, early, and late deaths following trauma with the late deaths occurring several days to weeks after the initial injury. The cause of death in this phase was most commonly due to sepsis and MODS. However, since this

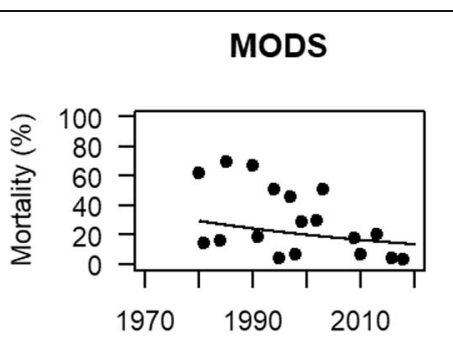

End of data collection (year)

ARDS

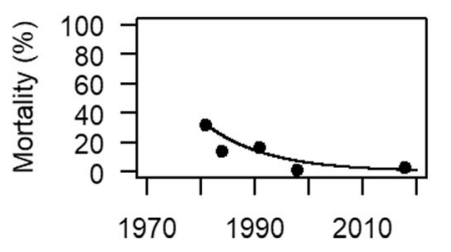

End of data collection (year)

Sepsis

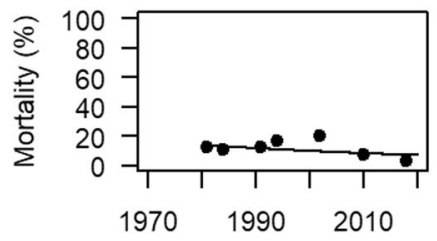

\section{Brain injury}

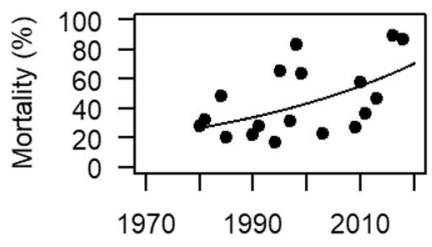

End of data collection (year)

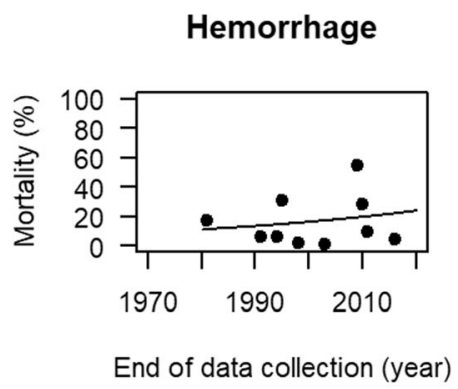

End of data collection (year)

Fig. 2 Changes in all-cause mortality in polytrauma patients admitted to the ICU since 1966. Each study is represented by a circle, of which the size is proportional to the number of subjects in the study 
MODS

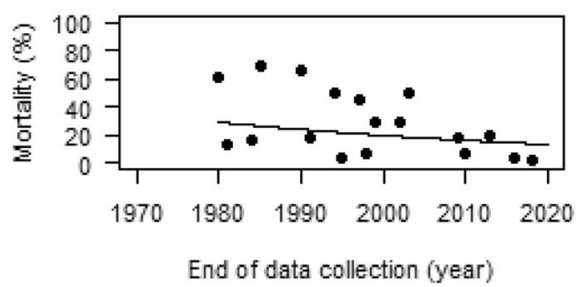

ARDS

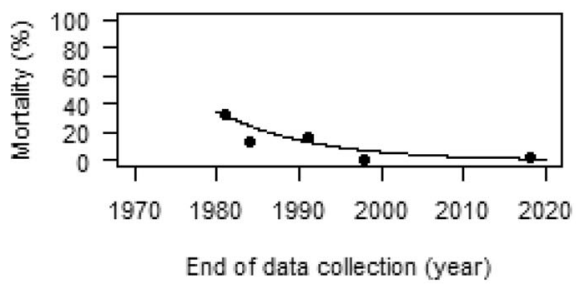

Sepsis

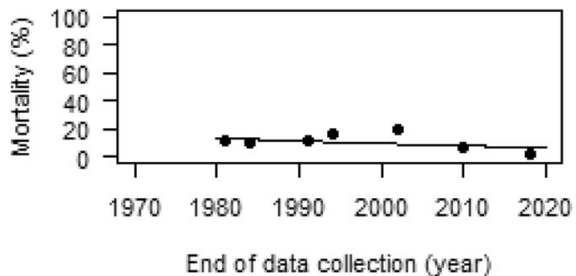

Brain injury

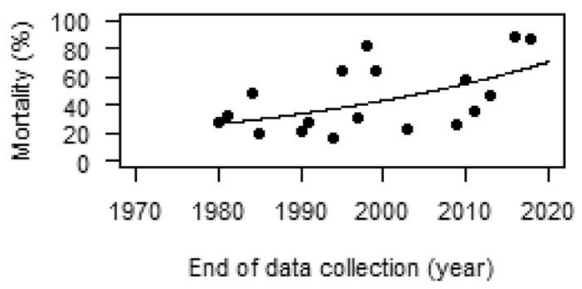

Hemorrhage

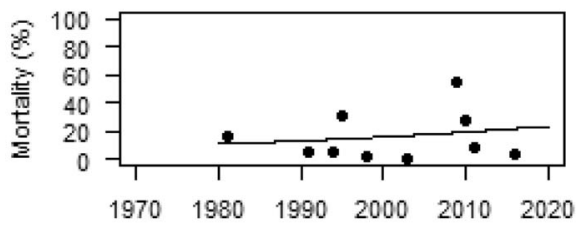

End of data collection (year)

Fig. 3 Relative contribution of cause-specific mortality to all-cause mortality in polytrauma patients admitted to the ICU since 1966. Different panels show the relative contribution of different causes of death

classification system is over 30 years old, this trimodal distribution does not reflect the current situation anymore, as shown in previous studies [6].

Probably many factors, both pre-hospital and inhospital, have contributed to the decrease in mortality throughout the past decades. Preventive strategies and legislation, such as obligatory use of seatbelts, as well as advances in diagnostic tools, resuscitation protocols, and peri-operative and surgical procedures have played an important role [2, 3, 44-47]. In addition, many improvements in trauma care regarding prevention and treatment of MODS/ARDS/sepsis have potentially led to the observed shift towards a larger relative contribution of brain injury-related death. According to Nast-Kolb et al. MODS-related mortality decreased due to an improved overall performance of trauma management and ICU care [17]. They identified several specific, major changes such as volume resuscitation, mechanical ventilation with airway pressure limitation, damage control treatment and early enteral nutrition as being of most importance.

High brain injury-related mortality could partially be explained by the trauma mechanism. Brain injury is often a consequence of blunt injury. It can be divided in primary brain injury, resulting in direct neuronal damage from the accident, and in secondary injury occurring at a later stage due to hypoxemia, hypotension, seizures, and intra-cranial hypertension. Secondary injury is a major contributor to mortality [16, 48]. According to Hadfield et al., secondary insults are preventable and treatable, and the main aim of critical care must be to prevent such secondary insults [16]. However, hypoxemia and hypotension may remain important causes of mortality, as they are complications of massive hemorrhage, which often used to be fatal at the site of the accident or in the emergency department, but is not anymore.

Interestingly, hemorrhage-related death in the ICU increased over time. This is in contrast with a large review showing that exsanguination-related death decreased over time (approximately $20 \%$ in 20 years) when the entire trajectory from the pre-hospital phase until the ICU was observed [3]. The authors suggested that the improvements in hemorrhage management and implementation of ATLS decreased mortality within $60 \mathrm{~min}$ after admission $[49,50]$. Also, rapid diagnostics with 24-h access to an onsite CT scanner and the introduction of the damage-control approach further reduced the probability of exsanguination soon after hospital admission [5153]. Before the introduction of damage control 


\section{Geographical differences in trauma mechanism}

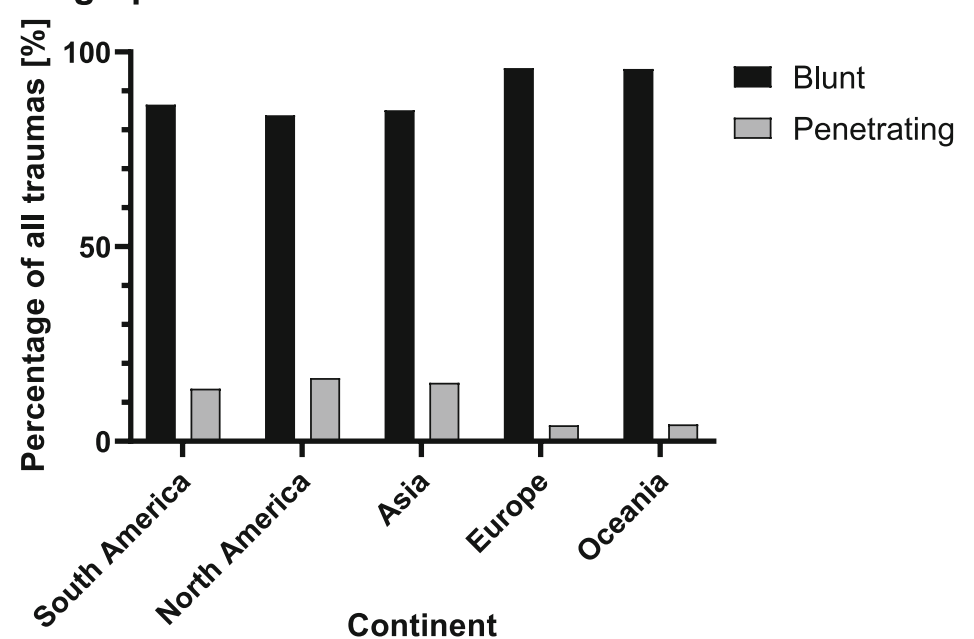

a Geographical differences in trauma mechanism divided in blunt and penetrating trauma between North America, Asia, Oceania and Europe. North America showed the highest percentage of penetrating injuries, whilst Europe has the most blunt injuries

\section{Cause of mortality per continent}

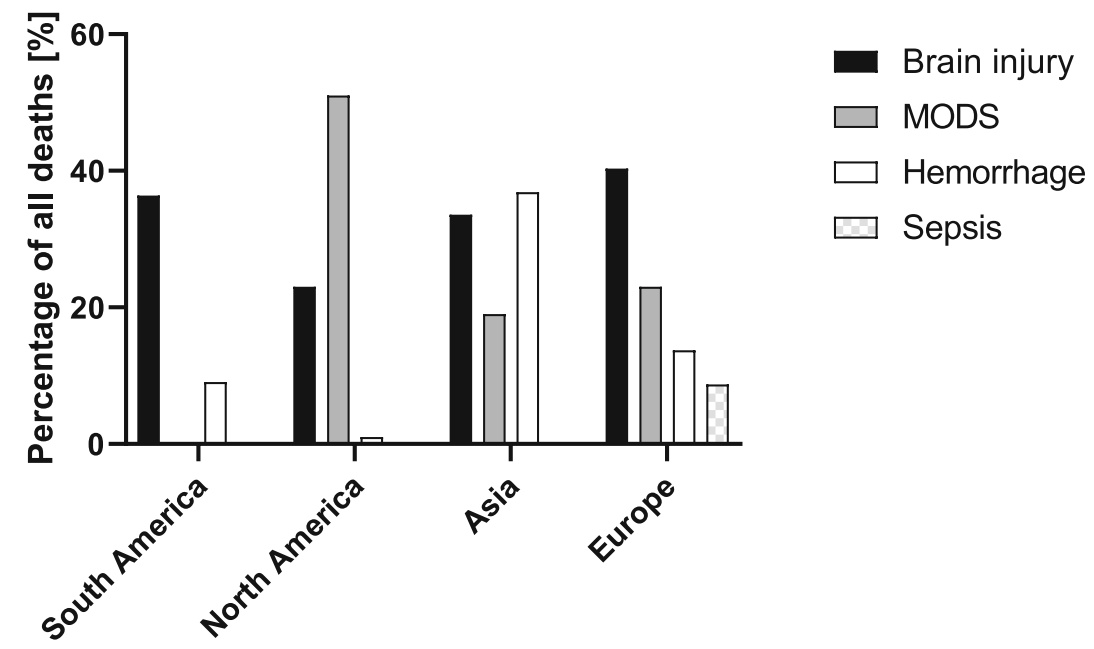

\section{Continent}

b Cause of mortality per continent. MODS was most prevalent in North America, hemorrhage in Asia and brain injury in Europe

Fig. 4 a Geographical differences in trauma mechanism divided in blunt and penetrating trauma between North America, Asia, Oceania, and Europe. North America showed the highest percentage of penetrating injuries, while Europe has the most blunt injuries. b Cause of mortality per continent. MODS was most prevalent in North America, hemorrhage in Asia, and brain injury in Europe 
resuscitation about 20 years ago, surgeons would operate and perform definitive interventions. This often led to metabolic derangement and/or death as severely injured patients frequently do not have the physiological reserve to undergo definitive surgery. On the other hand, nowadays, patients may survive the initial phase of trauma care in the ED and operating theater but may bleed out in the ICU due to new onset or uncontrolled surgical bleeding. Our findings suggest that there is a relative increase (in relation to a decrease in other causes of mortality) in exsanguination once admitted to the ICU.

One of the studies included in this review studied changes in ICU mortality from exsanguination over a 15-year period and found no changes [22]. Considering these findings, it may be worthwhile to focus on preventative and therapeutic options for exsanguination in the ICU setting.

Analysis of the data per continent showed slight differences in all-cause mortality. Alternatively, penetrating injuries were most common in North America which has been previously reported [16, 54]. We recommend more research on differences between continents and countries and the influence of different trauma systems on these variances to create learning opportunities and improvements in global trauma care.

This review has several limitations. First, the term "polytrauma", one of our inclusion criteria, has always been a topic of debate in literature $[35,55]$. Several of our included studies used different definitions, e.g. ISS > 15 by Fröhlich et al. [31] and ISS $>25$ by Lauwers et al. [12] (Table 1). A start at gaining consensus was made with the international meeting in 2012 [35]. Further work should build upon this meeting and should focus on estimating the risk of mortality and predicting the requirement of therapeutic care on an individual basis. This will help to apply new findings to the right patients and in comparing study results more accurately. Similarly, the terms MODS, ARDS and sepsis were defined differently in different studies (Appendix 2). Also, whereas some studies looked at all deaths during ICU admission, others included solely data from a predefined period, such as 30-day ICU mortality. Yet, study outcomes were compared in this study as these contain the best data currently available. Also on other levels the included study populations were similar, but not entirely equal, e.g., Lauwers et al. [12] only included patients suffering from blunt trauma, while other authors also included penetrating trauma $[13,15,20]$.

A second limitation is the extensive period covered in this review with a relatively small number of included articles. We suspect that more studies reported all-cause mortality, but if these numbers were not reported in the title or abstract, these articles were not identified by our search (Fig. 1). This large time span might have introduced bias, e.g., due to changes in causes of death that were of interest in the concerning time period or due to the development of establishing specialized trauma centers, e.g., for neurotrauma. Another limitation concerns a substantial number of included articles reported on data from the German trauma registry, which limits the generalizability of our findings. Also, in this review work-related injury is reported as a trauma mechanism-as do many article references in our review-although strictly it is not a trauma mechanism by itself. Rather, it is an umbrella term for trauma mechanisms, such as fall from height, falling objects, crushing injuries, and machinery injuries. A final limitation is that several studies provided data based on relatively long study periods of 10,15 , and 20 years $[14,19,22]$. Since studies were analyzed based on the end of data collection, rather than the years from which information was obtained, this could have influenced the results of this review.

\section{Conclusion}

In conclusion, in this review of polytrauma patients admitted to the ICU, the all-cause mortality decreased over the last decades. This decline could be considered a success of the improvements in trauma care. Before the turn of the century MODS was the leading cause of death, whereas nowadays it is brain injury.

\section{Appendix 1. Search strings}

\section{PubMed}

((“Multiple Trauma”[Mesh] OR polytrauma [tiab] OR "multiple trauma" [tiab] OR "massive trauma" [tiab] OR "multiple injury" [tiab] OR "polytraumatized patient"" [tiab] OR "multiple trauma" [tiab] OR "severely injur" [tiab]) AND ("Intensive Care Units"[Majr] OR ICU* [tiab] OR "Intensive Care Unit"* [tiab] OR "intensive care department" [tiab] OR "intensive treatment unit" [tiab]) AND ("Mortality"[Mesh] OR mortality [tiab] OR death [tiab] OR casualt" [tiab] OR outcome* [tiab]))

Embase

('multiple trauma'/exp OR 'massive trauma':ti,ab,kw OR 'multiple injury'tti,ab,kw OR polytrauma:ti,ab,kw OR 'polytraumatized patient':ti,ab,kw OR 'multiple trauma': ti,ab,kw) AND ('intensive care unit'/exp OR icu:ti,ab,kw OR icus:ti,ab,kw OR 'intensive care department':ti,ab,kw OR 'intensive care units':ti,ab,kw OR 'intensive treatment unit':ti,ab,kw OR 'intensive care':ti,ab,kw OR 'special care unit':ti,ab,kw) AND ('mortality'/exp OR death:ti,ab,kw)

\section{Appendix 2. Further analyses on geographical differences}

Differences in the ratio between penetrating and blunt trauma were analyzed. Summary statistics (percentages) are presented here. Because of the limited amount of 
data, no comparative statistical tests were performed. Seventeen articles included both trauma types in their study population and reported complete data (North America (USA): $n=3[19,27,39]$, South America: $n=2$ [40, 41], Asia: $n=2$ [20, 21], Oceania (Australia): $n=2$ [24, 30], Europe: $n=8[15,16,22,23,29,31-33])$. Weighted averages per continent were calculated based on patient numbers. In all five continents, the majority of the traumas were blunt (Fig. 4a). North America had the highest percentage of penetrating trauma (16\%), followed by Asia (15\%), South America (13\%), and then Europe and Oceania (both 4\%).

Further differences in the causes of mortality per continent were studied. The four most common causes were selected: brain injury, MODS, hemorrhage, and sepsis. Fourteen articles reported complete data and were included in this analysis (North America (USA): $n=1$ [19], South America: $n=1$ [41], Asia: $n=2$ [20, 21], Europe: $n=10$ [12-17, 22, 23, 32, 34]). Again, weighted averages were calculated. MODS was highest in North America (51\% of all deaths), while brain injury was most common in Europe (40\%), and hemorrhage was most prevalent in Asia (37\%) (Fig. 4b). Over time brain injuryrelated mortality substantially increased in Europe, whereas MODS-related death decreased substantially. It should be noted that the number of included articles per continent is small and that, as a consequence, there is a substantial risk of bias, e.g., over time the interest in reporting (different) causes of death may have changed and specialized trauma centers may have been established.

\section{Abbreviations \\ ARDS: Acute respiratory distress syndrome; ATLS: Advanced trauma and life support; CAPS: Critical Appraisal Skills Programme; CT: Computed tomography; ICU: Intensive care unit; MINORS: Methodological Index for Non-Randomized Studies instrument; MODS: Multiple organ dysfunction syndrome; PRISMA: Preferred Reporting Items for Systematic Reviews and Meta-Analyses; ROBINS-I: Risk of Bias in Non-Randomized Studies of Interventions}

\section{Acknowledgements}

Not applicable

\section{Grant support}

None

\section{Authors' contributions}

All authors were involved in designing this study. JvB, MN, and KvW composed the search string. JVB and MN performed the screening and selection of articles of interest, reviewed the quality of all included articles and collected the data. JvB performed the data analyses, which were checked by $\mathrm{NM}, \mathrm{KvW}, \mathrm{MH}$, and RG. All authors were involved in structuring and writing the manuscript. All authors read and approved the final manuscript.

\section{Funding}

No funding was obtained for this study

\section{Availability of data and materials}

The datasets used and/or analyzed during the current study are available from the corresponding author on reasonable request.

Ethics approval and consent to participate

Not applicable

\section{Consent for publication}

Not applicable

\section{Competing interests}

The authors declare that they have no competing interests

\section{Author details}

${ }^{1}$ Department of Trauma Surgery, University Medical Center Utrecht, Heidelberglaan 100, 3585 GA Utrecht, The Netherlands. ${ }^{2}$ Department of Clinical Epidemiology, Leiden University Medical Center, Albinusdreef 2, 2333 ZA Leiden, The Netherlands.

Received: 13 July 2020 Accepted: 19 August 2020

Published online: 30 September 2020

\section{References}

1. World Health Organisation, Health topics - injury, 2014

2. Lansink KW, Gunning AC, Spijkers AT, et al. Evaluation of trauma care in a mature level I trauma center in the Netherlands: outcomes in a Dutch mature level I trauma center. World J Surg. 2013;37:2353-9.

3. Pfeifer R, Tarkin IS, Rocos B, et al. Patterns of mortality and causes of death in polytrauma patients--has anything changed? Injury. 2009;40:907-11.

4. Baker CC, Oppenheimer L, Stephens B, et al. Epidemiology of trauma deaths. Am J Surg. 1980;140:144-50.

5. Trunkey DD. Trauma. Accidental and intentional injuries account for more years of life lost in the U.S. than cancer and heart disease. Among the prescribed remedies are improved preventive efforts, speedier surgery and further research. Sci Am. 1983;249:28-35.

6. Evans JA, van Wessem KJ, McDougall D, et al. Epidemiology of traumatic deaths: comprehensive population-based assessment. World J Surg. 2010;34:158-63.

7. (PRISMA) PRIFSRaM-A, 2015.

8. Ouzzani M, Hammady H, Fedorowicz Z, et al. Rayyan-a web and mobile app for systematic reviews. Syst Rev. 2016;5:210.

9. Sterne JA, Hernan MA, Reeves BC, et al. ROBINS-l: a tool for assessing risk of bias in non-randomised studies of interventions. BMJ. 2016;355:i4919.

10. Programme CAS Checklist, 2018.

11. Slim K, Nini E, Forestier D, et al. Methodological index for non-randomized studies (minors): development and validation of a new instrument. ANZ J Surg. 2003;73:712-6.

12. Lauwers LF, Rosseel $P$, Roelants $A$, et al. A retrospective study of 130 consecutive multiple trauma patients in an intensive care unit. Intensive Care Med. 1986;12:296-301.

13. Regel G, Lobenhoffer P, Grotz M, et al. Treatment results of patients with multiple trauma: an analysis of 3406 cases treated between 1972 and 1991 at a German level I trauma center. J Trauma. 1995;38:70-8.

14. Aufmkolk M, Majetschak M, Voggenreiter $G$, et al. Follow-up and prognosis of severe accidental trauma in the aged. Unfallchirurg. 1997;100:477-82.

15. Dereeper E, Ciardelli R, Vincent JL. Fatal outcome after polytrauma: multiple organ failure or cerebral damage? Resuscitation. 1998;36:15-8.

16. Hadfield RJ, Parr MJ, Manara AR. Late deaths in multiple trauma patients receiving intensive care. Resuscitation. 2001;49:279-81.

17. Nast-Kolb D, Aufmkolk M, Rucholtz S, et al. Multiple organ failure still a major cause of morbidity but not mortality in blunt multiple trauma. J Trauma. 2001;51:835-41 discussion 841-832.

18. Vignesh TA, S A, Kamat V. Outcome in patients with blunt chest trauma and pulmonary contusions. Indian Journal of Critical Care Medicine. 2004:8:73-7.

19. Ciesla DJ, Moore EE, Johnson JL, et al. A 12-year prospective study of postinjury multiple organ failure: has anything changed? Arch Surg. 2005; 140:432-8 discussion 438-440.

20. Zhang $L Y$, Yao $Y Z$, Jiang DP, et al. Surgical treatment strategy for multiple injury patients in ICU. Chin J Traumatol. 2011;14:42-5.

21. Chen W, Wang J, Feng QL, et al. The treatment of severe and multiple injuries in intensive care unit: report of 80 cases. Eur Rev Med Pharmacol Sci. 2014;18:3797-801. 
22. Di Saverio S, Gambale G, Coccolini F, et al. Changes in the outcomes of severe trauma patients from 15-year experience in a Western European trauma ICU of Emilia Romagna region (1996-2010). A population crosssectional survey study. Langenbecks Arch Surg. 2014;399:109-26.

23. van Wessem KJP, Leenen LPH. Reduction in mortality rates of postinjury multiple organ dysfunction ayndrome: a shifting paradigm? A prospective population-based cohort study. Shock. 2018;49:33-8.

24. Moore PG, James OF, Byth PL, et al. Factors affecting outcome after chest injury. Anaesth Intensive Care. 1985;13:362-9.

25. Herve C, Gaillard M, Huguenard P. Early medical care and mortality in polytrauma. J Trauma. 1987;27:1279-85.

26. Kivioja A. Factors affecting the prognosis of multiply injured patients: an analysis of 1169 consecutive cases. Injury. 1989;20:77-80.

27. Goins WA, Reynolds HN, Nyanjom D, et al. Outcome following prolonged intensive care unit stay in multiple trauma patients. Crit Care Med. 1991;19: 339-45.

28. Probst C, Pape $\mathrm{HC}$, Hildebrand F, et al. 30 years of polytrauma care: an analysis of the change in strategies and results of 4849 cases treated at a single institution. Injury. 2009:40:77-83.

29. Wafaisade A, Lefering $R$, Bouillon B, et al. Epidemiology and risk factors of sepsis after multiple trauma: an analysis of 29,829 patients from the Trauma Registry of the German Society for Trauma Surgery. Crit Care Med. 2011;39:621-8.

30. Dewar DC, Tarrant SM, King KL, et al. Changes in the epidemiology and prediction of multiple-organ failure after injury. J Trauma Acute Care Surg. 2013;74:774-9.

31. Frohlich $M$, Lefering $R$, Probst $C$, et al. Epidemiology and risk factors of multiple-organ failure after multiple trauma: an analysis of 31,154 patients from the TraumaRegister DGU. J Trauma Acute Care Surg. 2014;76:921-7 discussion 927-928.

32. van Wessem KJP, Leenen LPH. Incidence of acute respiratory distress syndrome and associated mortality in a polytrauma population. Trauma Surg Acute Care Open. 2018;3:e000232.

33. Brilej D, Stropnik D, Lefering $R$, et al. Algorithm for activation of coagulation support treatment in multiple injured patients--cohort study. European Journal of Trauma and Emergency Surgery. 2017:43:423-30.

34. Dehne MG, Sablotzki A, Mühling J, et al. Long-term monitoring of renal function in poly-traumatized intensive care patients. Renal failure. 2002;24:493-504.

35. Pape $\mathrm{HC}$, Lefering $\mathrm{R}$, Butcher $\mathrm{N}$, et al. The definition of polytrauma revisited: an international consensus process and proposal of the new 'Berlin definition'. J Trauma Acute Care Surg. 2014;77:780-6.

36. Regel $G$, Grotz $M$, Weltner $T$, et al. Pattern of organ failure following severe trauma. World J Surg. 1996;20:422-9.

37. $\mathrm{PDM}, \mathrm{KH}, \mathrm{H} \mathrm{H}$, et al. Acute physiology and chronic health evaluation (APACHE) III score compared to trauma-injury severity score (TRISS) in predicting mortality of trauma patients. Emergency. 2016;4:88-91.

38. Stiletto R, Hünerkopf $M$, Schnabel $M$, et al. Continuous stroke volume monitoring as "hemodynamic online monitoring" in polytrauma intensive care patients: technically possible--clinically necessary? Der Unfallchirurg. 2001;104:1043-7.

39. Rixen D, Siegel JH. Metabolic correlates of oxygen debt predict posttrauma early acute respiratory distress syndrome and the related cytokine response. The Journal of trauma. 2000;49:392-403.

40. Freitas $A D$, Franzon O. Lactate as predictor of mortality in polytrauma. Arquivos brasileiros de cirurgia digestiva: $A B C D=$ Brazilian archives of digestive surgery. 2015;28:163-6.

41. R C, M X, M, L L, et al. Characteristics of trauma patients admitted to the intensive care unit of a general hospital in Chile. Características de los pacientes traumatizados que ingresan a la $\mathrm{UCl}$ de un hospital general en Chile. 2013;141:1389-94.

42. Ruscelli P, Buccoliero F. Outcomes in polytrauma: comparison between the results achieved in the Cesena Trauma Centre and in the Regional Registry of a (RRGT) of Emilia Romagna, Italy. Annali italiani di chirurgia. 2014;85:6-15.

43. H-C P, D R, M G, et al. Reticuloendothelial system activity and organ failure in patients with multiple injuries. Arch Surg. 1999;134:421-7.

44. Lansink KW, Leenen LP. History, development and future of trauma care for multiple injured patients in the Netherlands. Eur J Trauma Emerg Surg. 2013;39:3-7

45. Ermolov AS, Abakumov MM, Sokolov VA, et al. Structure of hospital lethality in polytrauma and ways to reduce it. Khirurgiia (Mosk). 2006:16-20.

46. Meier J, Habler $\mathrm{O}$. The polytrauma patient in the intensive care unit. Anasthesiol Intensivmed Notfallmed Schmerzther. 2007;42:724-30.
47. Kristiansen T, Soreide K, Ringdal KG, et al. Trauma systems and early management of severe injuries in Scandinavia: review of the current state. Injury. 2010;41:444-52.

48. Sauaia A, Moore FA, Moore EE, et al. Epidemiology of trauma deaths: a reassessment. J Trauma. 1995;38:185-93.

49. van Olden GD, Meeuwis JD, Bolhuis HW, et al. Clinical impact of advanced trauma life support. Am J Emerg Med. 2004;22:522-5.

50. van Olden GD, Meeuwis JD, Bolhuis HW, et al. Advanced trauma life support study: quality of diagnostic and therapeutic procedures. J Trauma. 2004;57:381-4.

51. Browne J, Coats TJ, Lloyd DA, et al. High quality acute care for the severely injured is not consistently available in England, Wales and Northern Ireland: report of a survey by the Trauma Committee, The Royal College of Surgeons of England. Ann R Coll Surg Engl. 2006;88:103-7.

52. Lecky F, Woodford M, Yates DW. Trends in trauma care in England and Wales 1989-97. UK Trauma Audit and Research Network. Lancet. 2000;355:1771-5.

53. Rotondo MF, Schwab CW, McGonigal MD, et al. 'Damage control': an approach for improved survival in exsanguinating penetrating abdominal injury. J Trauma. 1993;35:375-82 discussion 382-373.

54. Soreide K. Epidemiology of major trauma. Br J Surg. 2009;96:697-8.

55. Paffrath $T$, Lefering $R$, Flohe $S$, et al. How to define severely injured patients? -- an Injury Severity Score (ISS) based approach alone is not sufficient. Injury. 2014:45(Suppl 3):S64-9.

56. Dresing K, Armstrong WW, Leip C-L, et al. Real-time assessment of hepatic function is related to clinical outcome in critically ill patients after polytrauma. Clinical biochemistry. 2007:40:1194-200.

\section{Publisher's Note}

Springer Nature remains neutral with regard to jurisdictional claims in published maps and institutional affiliations.

\section{Ready to submit your research? Choose BMC and benefit from:}

- fast, convenient online submission

- thorough peer review by experienced researchers in your field

- rapid publication on acceptance

- support for research data, including large and complex data types

- gold Open Access which fosters wider collaboration and increased citations

- maximum visibility for your research: over $100 \mathrm{M}$ website views per year

At $\mathrm{BMC}$, research is always in progress.

Learn more biomedcentral.com/submissions 